\title{
MARKETING ESTRATÉGICO Y COSTOS EN LA GLOBALIZACIÓN DE LOS MERCADOS.
}

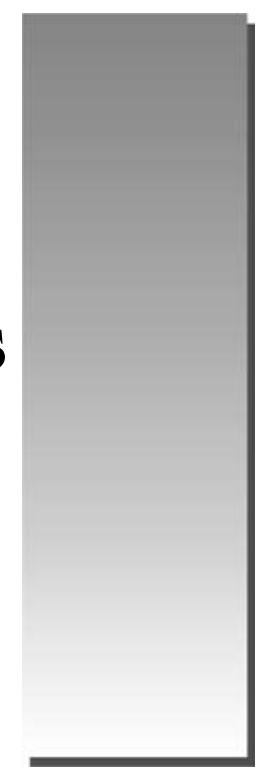

Jorge V. Mayurí Barrón (")

E-mail: jvmayuri@hotmail.com

\section{RESUMEN}

En el mercado global que vive la empresa -micro, pequeña, mediana o grande-, cualquiera que sea su volumen, tiene que ser competitiva. Para alcanzar este objetivo los marketeros acuden a herramientas tales como la auditoría y los costos. Así aparece un nueva disciplina: el marketing estratégico, basado en el principio enunciado por Peter Drucker: "Fabricad lo que podáis vender, antes que intentar vender lo que podáis fabricar".

En este artículo se pretende demostrar la importancia de la integración de las disciplinas de Auditoría y Costos que, como vasos comunicantes, se amalgaman al servicio de la empresa para ayudarla a alcanzar sus objetivos, haciendo un llamado de advertencia a los administradores, contadores y economistas a interesarse en estos temas de vigente actualidad.

Palabras Clave: Mercado Global, Auditoría, Costos.

\begin{abstract}
In the global marketplace that live micro-enterprise, small, medium or large, whatever its size, it has to be competitive. To achieve this objective, marketers go to tools such as Auditing and Costs. This is how appears a new discipline: Strategic Marketing, based on the principle stated by Peter Drucker: "Make what you can sell, rather than trying to sell what you can make".

This article aims to demonstrate the importance of integrating Auditing and Costs disciplines which are communicating vessels working together to be of service to the company to achieve its objectives, making a warning call to managers, accountants and economists to be interested on these current issues.
\end{abstract}

Keywords: Global Marketplace, Auditing, Costs.

(") Doctor en Educación (UNMSM) y Magíster en Administración con Mención en Gestión Empresarial (UNMSM). Licenciado en Administración de Empresas (Universidad Ricardo Palma) con estudios de Post Grado en Derecho Aéreo y Espacial (UNMSM). Actualmente se desempeña como Profesor Asociado de la Facultad de Ciencias Administrativas de la UNMSM y USIL, y docente de Post Grado en diversas universidades. Capacitador Empresarial. 


\section{QUÉ ES EL MÁRKETING ESTRATÉGICO}

Un concepto fundamental que ha cambiado en 360 grados es la idea original del marketing que era "la realización de las actividades comerciales que dirigen el flujo de bienes y servicios del fabricante o productor al mercado", en el entendido que los mercados no existen para atender las necesidades de la empresa, sino que ésta existe para atender a las necesidades del mercado. Así vemos que en el sistema económico anterior a la Segunda Guerra Mundial el marketing se centraba, en proporcionar las necesidades básicas en un mercado de carencias y con clientes de mínima capacidad de consumo. $\mathrm{Y}$ tan pronto como mejoró su ingreso per cápita se produjeron una serie de cambios en la naturaleza de la demanda: más productos y servicios nuevos. Pero el impacto de la crisis económica inmersa en el sistema capitalista, con su consecuente reducción y estancamiento del consumo privado, obligó a las empresas a ajustar sus capacidades de producción en función de la demanda y a buscar nuevos mercados o nuevos productos.

Para superar esta situación aparece el marketing operacional que se apoya en los medios tácticos basados en la política del producto, distribución, precio y comunicación cuyo horizonte de acción se sitúa en el corto y mediano plazo. Eran tiempos de mercados cerrados, donde los países practicaban la política de sustitución de importaciones, donde el concepto exportación estaba fuera de las posibilidades de la empresa común. Se importaba más del mercado exterior que lo que se vendía hacia él.

La globalización cambió esta situación: las trabas internacionales desaparecieron y ahora es una moda corriente exportar al extranjero, por lo que el marketing estratégico tiene el objetivo de descubrir lo que necesita el mercado y actuar en consecuencia, orientando a las empresas hacia la satisfacción de necesidades que constituyan oportunidades económicas atractivas para ella, dirigiendo su horizonte en el mediano y largo plazo, basados en el principio generalmente aceptado de la empresa en marcha; esto es, situar la oferta en función de la demanda: vender lo que se produce o producir lo que se vende. ¿Y cómo lograrlo? Con el auxilio de los costos, la aplicación de estrategias de precios, estrategias cualitativas y de diferenciación supervisadas por una auditoría de cumplimiento de metas para tomar las medidas correctivas cuando no se cumpla con lo previsto en un periodo determinado.

\section{ESTRATEGIAS DE PRECIO}

Una de las herramientas más efectivas de mercadeo para promocionar un producto o servicio es el precio. Este aspecto afecta la imagen y la demanda, y nos ayuda a penetrar en un segmento específico del mercado. Las estrategias de precio deben ser consistentes con todas las metas y los objetivos del negocio.

Para seleccionar una estrategia de precio se debe analizar:

- El mercado meta.

- Los clientes.

- Los competidores directos e indirectos.

- Los riesgos.

- El impacto que el precio tendrá sobre la demanda del producto o servicio.

- ¿Cuánto el comprador estaría dispuesto a pagar por el producto o servicio?

En un negocio exitoso, el precio debe tomar en consideración el costo total y dejar un margen de ganancia.

\section{Precio para la Penetración en el Mercado}

Comúnmente se conoce como precio de introducción. Se establece un precio bajo para atraer a los consumidores y ganar gran participación en el mercado. Los almacenes y las tiendas de descuentos utilizan esta estrategia para penetrar un segmento en específico.

Muchas condiciones favorecen el fijar un precio bajo:

- Produce un mayor crecimiento en el mercado.

- Los costos de distribución y producción bajarán a medida que el volumen de ventas aumente.

- Ayuda a mantener fuera a la competencia.

\section{Descuentos}

La estrategia de precio puede incluir descuentos a clientes que compran con regularidad.

- Se pueden ofrecer descuentos a clientes que pagan con prontitud. Esta recompensa ayuda a la empresa a mantenerse estable, además 
que permite un flujo de efectivo y reduce los costos de cuentas por cobrar.

- Se pueden ofrecer descuentos por volumen de compra. El costo por unidad se reduce a medida que la cantidad del producto aumenta.

- Descuentos por temporadas, como incentivo a los consumidores para que compren durante épocas en que tradicionalmente se refleja una merma en las ventas.

\section{Igualar el Precio de la Competencia}

Es una táctica común usar el precio de la competencia como una guía para fijar sus propios precios.

\section{Análisis del Punto de Equilibrio}

Antes de decidir el precio de venta de un producto o servicio necesitamos saber primero cuánto nos cuesta producir. Una vez identificado el costo, se puede determinar el punto de equilibrio, donde no habrá ganancia ni pérdida de dinero en la venta o producción de un producto y en el ofrecimiento de un servicio.

Por ejemplo, si el costo de un producto o servicio es de US\$ 100 y el precio de venta es igual, éste será su punto de equilibrio: INGRESOS $=$ COSTOS. Para determinar el punto de empate es necesario conocer los costos totales fijos y calcular cuáles son los costos variables en los diferentes niveles de producción.

- Costos fijos. Son aquellos que no varían, tales como el alquiler (oficina, local, almacén), el equipo de oficina (computadoras, fax, escritorios), los seguros, los intereses, la depreciación de los equipos, el agua, la electricidad, el teléfono, los salarios de los empleados, etc.

- Costos variables. Son aquellos que varían con el volumen de la producción de un producto o de los servicios ofrecidos. Estos costos incluye las horas pagadas a una persona que se contrató para un proyecto especial, materia prima, etc. Existen algunos costos variables que no dependen específicamente de la cantidad de producción, tales como la publicidad y la promoción.

Antes de determinar el punto de equilibrio es necesario conocer los gastos fijos así como los costos variables.
5. ¿Cómo calcular la ganancia en el Punto de Equilibrio?

Pueden utilizarse las siguiente fórmulas:

$$
P E Q=C F / M C U
$$

Donde:

PEQ $=$ Punto de Equilibrio en Cantidades.

$\mathrm{CF}=$ Costo Fijo.

MCU = Margen de Contribución Unitario.

Margen de Contribución $=$ Ventas Netas menos Costo Variable.

$$
\mathrm{PEM}=\mathrm{CF} / \% \mathrm{MC}
$$

Donde:

PEM $=$ Punto de Equilibrio Monetario

$\mathrm{CF}=$ Costo Fijo

$\% \mathrm{MC}=$ Porcentaje del Margen de Contribución.

\section{6. ¿Cómo calcular el Punto de Equilibrio Monetario?}

Por ejemplo, vamos a tratar de determinar la tarifa por hora apropiada para un Consultor de Negocio. El costo total fijo es S/. 30,000. El costo variable por unidad es S/. 15.00 (la hora del Consultor) y el precio de venta por unidad es $\mathrm{S} / .30 .00$ (hora de consulta).

$$
\begin{aligned}
& \text { PEM }=\text { CF } / \% M C \\
& \text { CF }=\text { S/. } 30,000 \% M C=30-15=15 \\
& (15 / 30)^{*} 100=50 \%=0.5 \\
& \text { S/.30,000/0.5 }=\text { S/. 60,000 } \\
& \text { S/.30,000/ }-(15 / 30)=S / .60,000
\end{aligned}
$$

Este negocio necesita vender S/. 60,000 sólo para cubrir los costos. Si no genera esta cantidad entonces tendrá pérdidas; si sobrepasa los S/. 60,000 entonces tendrá un ingreso.

\section{Determinar el precio para obtener ganancia: precio basado en costo.}

Después de determinar el punto de empate, existen estrategias para establecer precios con el propósito de alcanzar otros objetivos financieros, tales como:

- Establecer un precio alto para obtener ganancias altas inicialmente. Esta estrategia se utiliza para recobrar los altos costos de investigación y desarrollo o maximizar las ganancias antes que los competidores entren al mercado. Las farmacéuticas utilizan esta estrategia cuando introducen nuevos medicamentos. 
- Establecer un precio bajo en uno o más productos para hacer ventas rápidamente para apoyar a otro producto que está en desarrollo. Algunas compañías adoptan esta estrategia cuando necesitan aumentar el flujo de efectivo.

- Establecer diversos precios hasta conocer la meta que desea obtener en ganancias. Por ejemplo, si desea una ganancia de un $20 \%$ por unidad y el costo por unidad es de $S / .10$, puede establecer un precio de S/. 12.

8. Determinar el precio para obtener ganancia: precio basado en valor.

¿Cuán alto puede ser el precio después que el producto o servicio ha salido al mercado? Para entender la percepción del consumidor sobre el valor de su producto o servicio se recomienda utilizar un criterio subjetivo como las preferencias del consumidor, los beneficios del producto, la conveniencia, la calidad del producto, la imagen de la compañía y las alternativas que ofrece la competencia.

- ¿Qué piensan los consumidores que reciben a cambio por su dinero?

- ¿Ahorran dinero o tiempo con la compra de su producto o servicio?

- ¿Obtienen alguna ventaja competitiva con el uso de su servicio?

- ¿Es más conveniente usar su servicio que tratar de hacerlo por ellos mismos?

- ¿Cuáles son las opciones del consumidor?

- ¿Cuál es el precio de la competencia?

Con esta información se puede determinar el precio máximo que el consumidor estará dispuesto a pagar por los beneficios recibidos.

\section{ESTRATEGIAS CUALITATIVAS}

\section{Beneficios y rasgos distintivos del producto}

Los productos pueden ser descritos en términos de sus rasgos distintivos y sus beneficios.

- Los rasgos distintivos son las características del producto que resaltan sus beneficios, tales como el tamaño, el color, el diseño, la función y los materiales utilizados para manufacturar el producto.

- Beneficios, son las ventajas del producto para el consumidor.

Mientras los rasgos distintivos del producto son fáciles de detectar y describir, en los bene- ficios del producto es necesario tener una habilidad para mostrarlos ya que muchas veces son intangibles. Los beneficios más atractivos son aquellos que ofrecen una recompensa emocional o financiera al consumidor.

Las recompensas emocionales hacen fluir la gama de emociones humanas que le permite al consumidor mejorarse en cierta forma. Por ejemplo, enviar flores a un familiar o a un amigo le permite a las personas expresar amor; adquirir productos que son hechos con material reciclado le ofrece la oportunidad al comprador de responsabilizarse por el ambiente.

Los productos que ofrecen una recompensa financiera le permiten al comprador:

- Ahorrar dinero (plan de descuentos).

- Hacer dinero (programas de computadoras para el manejo de un negocio desde la casa).

- Ganar conveniencia y tiempo (comidas de microondas).

\section{Descubriendo los beneficios del producto}

Para identificar los beneficios del producto se debe considerar el punto de vista del consumidor. Además de ponerse mentalmente en los zapatos del consumidor, es necesario hacer un estudio para conocer los beneficios del producto. Puede que los resultados brinden información que nunca se consideró acerca del producto.

Se pueden desarrollar diferentes sistemas para monitorear y rastrear los beneficios del producto:

- Pida a los clientes sugerencias para mejorar el producto.

- Preste atención a las quejas de los consumidores.

- Esté atento a lo que dice el consumidor.

- Vigile a la competencia.

3. ¿Por qué es importante entender cuáles son los beneficios o rasgos distintivos de nuestro producto?

Entender los beneficios y rasgos distintivos del producto nos permite:

- Describir el producto en una forma más convincente para el consumidor.

- Explicar cómo el producto es mejor que el de la competencia.

- Fijar un precio.

- Crear estrategias efectivas. 


\section{ESTRATEGIA DE DIFERENCIACIÓN}

Los productos pueden ser únicos (productos especiales) o visualmente diferentes a los productos de la competencia (artículos de consumo). Los productos especiales no son necesariamente mejores que los artículos de consumo, pero requieren diferentes estrategias de mercado. Una estrategia para los productos especiales es la diferenciación. La comparación de nuestros productos con los de la competencia nos permitirá posicionarnos efectivamente.

Un trabajo en el que continuamente cambian las necesidades y deseos de las personas, dada la dinámica del mercado, tiene que ser constante en el tiempo. Sólo así se podrán dar respuestas satisfactorias a las demandas del mercado en cada momento, como dice Philip Kotler: "Las compañías exitosas serán las pocas que logren que su marketing cambie tan rápido como su mercado". Por eso hoy en día el triunfo viene dado no por la lucha de productos sino de percepciones. Entonces para conocer nuestra situación en el mercado y el posicionamiento en la mente del cliente, tendremos que realizar de forma regular una Auditoría de Marketing.

\section{AUDITORÍA DE MARKETING}

Si por un momento los empresarios se detuvieran a conocer qué es una Auditoria de Marketing, en qué consiste y cuáles son sus beneficios reales, se darían cuenta de que, ante todo, es un aliado empresarial. Y, ¿qué hacen los aliados? La respuesta parece evidente: colaborar con nosotros en los momentos boyantes para que la situación se torne aún más rentable, y cooperar con nosotros en los momentos de vacas flacas como el actual, para ayudarnos a vencer al mayor enemigo que puede tener cualquier empresa, que es la crisis.

La Auditoría de Marketing no es ni más ni menos que una herramienta de trabajo que permite a la empresa analizar y evaluar los programas y acciones del área Comercial y de Marketing, así como su adecuación al entorno y a la situación del momento. Dicho de forma más práctica, examina todas las áreas de la compañía y averigua las oportunidades y amenazas o, lo que es aún más importante, indica las áreas de mejora sobre las que hay que actuar para aumentar la rentabilidad de la empresa.
Para que ésta sea realmente efectiva tiene que cumplir una serie de condicionantes obligatorios que son:

- Sistemática. Debe seguir una secuencia ordenada en cada una de las fases necesarias para realizar el diagnóstico.

- Completa. Debe analizar cada uno de los factores que influyen en todas y cada una de las variables de marketing y en su efectividad.

Pero además, una Auditoría de Marketing efectiva ha de ser independiente, de forma que garantice un análisis objetivo. Y la mejor forma de lograr esa objetividad es encargando la realización de la auditoría a profesionales especializados externos a la empresa pero que, al mismo tiempo, puedan integrarse plenamente con ella. Es más, sólo una buena comunicación entre empresa y auditor puede dar los frutos deseados.

Pero la verdadera utilidad de la Auditoría empieza cuando al saber de dónde partimos podemos empezar a crear, planificar y marcar objetivos. En definitiva, para posicionarnos con éxito en un mercado cada vez más competitivo debemos dar un paso más: adentrarnos en las fronteras del Marketing estratégico y utilizar el amplio abanico informativo y resolutivo que nos ofrecen las Auditorías de Marketing.

\section{COMENTARIO FINAL}

Nos llama a reflexión cómo el impacto de la globalización está obligando a los profesionales de distintas especialidades a integrarse en equipos multidisciplinarios, hasta antes impensables, para superar los problemas cada vez más complejos que plantea el mercado mundial. ¿No es acaso una llamada de atención a las Facultades de Administración, Contabilidad y Economía a fusionarse en una sola al interior de las universidades? Más aún, ¿la integración de sus respectivos Colegios Profesionales en una gran Federación? Sólo el tiempo dirá si estamos equivocados.

\section{BIBLIOGRAFÍA.}

Kotler, Philip. (2006). Dirección de Marketing. Ciudad, Editorial Prentice Hall.

Kotler, Philip. (2005). Preguntas más frecuentes sobre Marketing. Barcelona, España, Editorial Granica.

Westwood, John. (2007). Cómo crear un Plan de Márketing. España, Editorial Gedisa. 